\title{
Principales herramientas epigenéticas para el diagnóstico y seguimiento de neoplasias hematológicas
}

\author{
Main epigenetic tools for the diagnosis \\ and monitoring of hematological malignancies
}

Juliana P. Sánchez-Álvarez MSc', Paola A. Acevedo-Toro MSc²

\begin{abstract}
Resumen: el análisis exhaustivo de los patrones de metilación del ADN es una parte fundamental para entender las bases moleculares del desarrollo y progresión de las neoplasias hematológicas, debido a que la hipermetilación en regiones promotoras afecta directamente vías carcinogénicas y conduce a la inactivación de genes involucrados en procesos celulares fundamentales como el ciclo celular y la apoptosis. En esta revisión de literatura se presenta una descripción de las técnicas más utilizadas para el estudio de la metilación: la reacción en cadena de la polimerasa específica de la metilación (MSP), el análisis combinado restricción bisulfito (COBRA), la secuenciación dependiente de bisulfito (BSP), la pirosecuenciación con bisulfito y las técnicas basadas en micromatrices; describiendo su principio, aplicación en la investigación de las neoplasias hematológicas y algunas de sus fortalezas y debilidades.
\end{abstract}

Palabras clave: metilación de ADN, neoplasias hematológicas, reacción en cadena de la polimerasa, secuenciación del ADN, análisis por micromatrices.

Abstract: the comprehensive analysis of DNA methylation patterns is important to understanding the molecular basis of development and progression of hematological malignancies. The hypermethylation in promoter regions directly affects carcinogenic pathways and leads to the inactivation of genes involved in fundamental cellular processes such as cell cycle and apoptosis. In this review are presented the most widely used techniques to DNA methylation analysis: methylation specific polymerase chain reaction (MSP), combined bisulfite restriction analysis (COBRA), bisulfite-sequencing polymerase chain reaction (BSP), bisulfite pyrosequencing and microarrays; describing its principles, usefulness in the hematological malignancies study, and some of its strengths and weaknesses.

'Microbióloga y Bioanalista. Estudiante de maestría en Microbiología y Bioanálisis, énfasis Hematología. Escuela de Microbiología, Universidad de Antioquia. Medellín, Colombia.

${ }^{2}$ Microbióloga y Bioanalista. MSc en Ciencias Básicas Biomédicas. Docente Escuela de Microbiología, Grupo de Investigación Hematopatología Molecular (HEMO). Universidad de Antioquia. Medellín, Colombia. Correspondencia: Calle 67 Número 53108, Bloque 5, oficina 435. Correo electrónico: micropao@gmail.com

Conflicto de intereses: las autoras declaran que no tienen conflicto de intereses Medicina \& Laboratorio 2015; 21: 43-62

Módulo 4 (Hematología), número 12. Editora Médica Colombiana S.A. $2015^{\odot}$

Recibido el 27 de enero de 2015; aceptado el 05 de febrero de 2015

Medicina \& Laboratorio Volumen 2I, Números I-2, 2015. 
Key words: DNA methylation, hematologic neoplasms, polymerase chain reaction, DNA sequencing, microarray analysis.

Sánchez-Álvarez JP, Acevedo-Toro PA. Principales herramientas epigenéticas para el diagnóstico y seguimiento de neoplasias hematológicas. Medicina \& Laboratorio 2015; 21: 43-62.

I a epigenética se puede definir como el estudio de los cambios heredables en la expresión Lgénica causados por mecanismos distintos a modificaciones en la secuencia del ADN [I]. Estos mecanismos desempeñan un papel clave en los procesos fisiológicos de los mamíferos, ya que determinan la especificidad en el crecimiento y la diferenciación de cada célula en el organismo, por tanto, un perfil de expresión génica anormal modifica la identidad celular, causando cambios en el fenotipo y aumento de la susceptibilidad a ciertas enfermedades. Los eventos epigenéticos están involucrados en múltiples procesos como el envejecimiento y en la patogénesis de múltiples enfermedades como las autoinmunes y los cánceres hematológicos, en las cuales ha sido ampliamente estudiado y ha ayudado a justificar el aumento de su prevalencia [2].

La metilación del ADN es quizá el mecanismo epigenético más comúnmente descrito en las neoplasias hematológicas [3]. Este proceso se produce por la transferencia de grupos metilo al carbono 5 (C5) de las citosinas que están presentes en el dinucleótido citosina-fosfato-guanina $(\mathrm{CpG})$ a partir de la S-adenosil metionina (SAM), un donante de metilos. Esta reacción es catalizada por enzimas ADN metiltransferasas (DNMTs) [4]. La hipermetilación ocurre en las islas CpG normalmente no metiladas, las cuales se encuentran localizadas en las regiones promotoras de los genes supresores de tumores, lo que produce la inactivación o silenciamiento de estos genes [5]. Por tal razón, los cambios en los patrones de metilación del ADN en diversos genes se han relacionado con la progresión de los cánceres hematológicos [6-9].

Las alteraciones epigenéticas representan una característica importante en el desarrollo del cáncer, incluso de las neoplasias hematológicas, cuyas características clínicas muestran una alta variabilidad interindividual y comprenden los cánceres que se originan a partir de órganos hematopoyéticos primarios (médula ósea y sangre), como los mielomas y las leucemias, y los procedentes de órganos linfoides secundarios (ganglios linfáticos), como los linfomas [10].

Para definir mejor el impacto de las alteraciones causadas por la metilación del ADN sobre la patogénesis de las neoplasias hematológicas es necesario establecer detalladamente los perfiles de metilación de cada una de ellas. De esta manera, se obtendrá una mejor comprensión del proceso de transformación y, posiblemente, de las implicaciones en el cuidado del paciente en las áreas de diagnóstico, pronóstico e intervenciones terapéuticas [ I l ]. Por lo tanto, cada vez es más necesario el diseño de nuevos métodos para la determinación de la metilación aberrante de los genes que brinden una imagen más completa de las vías celulares implicadas en cada tipo de neoplasia hematológica [12].

En este artículo se revisarán las técnicas para el análisis de los patrones de metilación del ADN más utilizadas en el estudio de las neoplasias hematológicas, exponiendo su principio, aplicación en la investigación de las neoplasias hematológicas y algunas de sus fortalezas y debilidades. 


\title{
Métodos de detección de la metilación del ADN
}

Inicialmente, el estudio de los patrones de metilación de secuencias individuales y específicas del ADN se fundamentaba casi exclusivamente en la digestión con endonucleasas sensibles e insensibles a la metilación [I3]. El ADN digerido con una enzima de restricción sensible a la metilación es cortado en o cerca del sitio de reconocimiento de la enzima en la secuencia de interés que no se encuentra metilada, pero no en aquellas que sí están metiladas. Posteriormente, el estado de metilación es determinado por el procedimiento de transferencia de Southern usando una sonda específica [14] o mediante el método de reacción en cadena de la polimerasa (PCR; del inglés, polymerase chain reaction) (véase figura I) [I5]. Entre las principales ventajas de esta técnica se encuentra que no requiere modificaciones de la secuencia del ADN, lo que lo hace un método relativamente simple y que previene el daño en el material genético; sin embargo, presenta ciertos inconvenientes como un análisis limitado, debido a la disponibilidad de sitios de restricción en el fragmento de interés y la posibilidad de digestiones incompletas que producen falsos positivos [16].

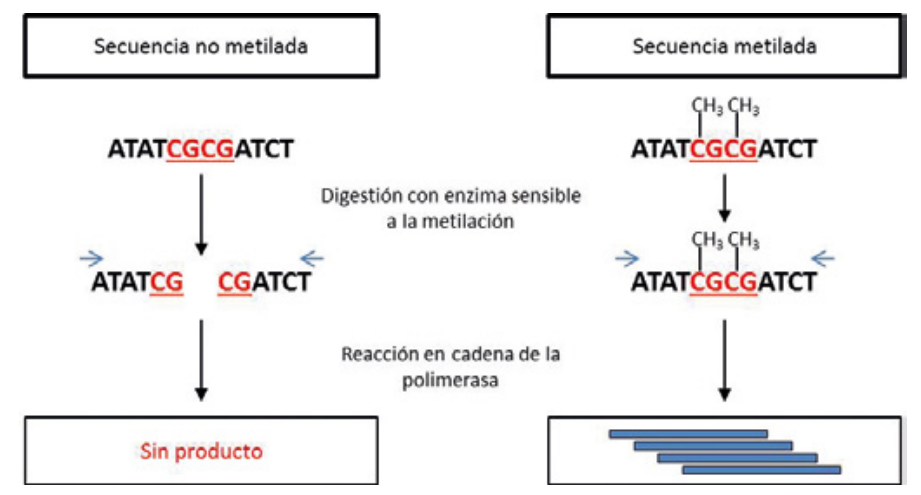

\begin{abstract}
Figura I. Esquema de la técnica basada en enzimas de restricción sensibles a la metilación combinada con la reacción en cadena de la polimerasa. El ADN es tratado con la enzima sensible a la metilación y, posteriormente, amplificado por reacción en cadena de la polimerasa. Cuando la secuencia se encuentra sin metilar la enzima corta en su sitio de reconocimiento, por lo tanto, no hay amplificado y no se encuentra producto de la reacción. Cuando la secuencia se encuentra metilada, los grupos metilo protegen de la digestión por la enzima de restricción y, por tanto, no se produce el corte de la secuencia en el sitio de reconocimiento de la enzima, permaneciendo intacta. En este caso la secuencia es amplificada, previo diseño de cebadores específicos, obteniendo el producto de reacción. Tomada y modificada de "CpG methylation analysis--current status of clinical assays and potential applications in molecular diagnostics: a report of the Association for Molecular Pathology" por AR Sepulveda y colaboradores, 2009, J Mol Diagn, II, p. 269. Copyright(C) 2009 por American Society for Investigative Pathology y la Association for Molecular Pathology.
\end{abstract}

Actualmente, la mayoría de las técnicas de detección de la metilación del ADN están basadas en el uso de enzimas de restricción y la previa conversión con bisulfito de sodio de la secuencia, la cual consiste en una serie de reacciones químicas (sulfonación, deaminación y desulfonación) que dan paso a la transformación de las citosinas no metiladas en uracilos, que serán convertidos en timinas durante la síntesis in vitro del ADN en la reacción en cadena de la polimerasa [17] (véase figura 2). 


\section{Reacción en cadena de la polimerasa específica de la metilación}

La reacción en cadena de la polimerasa específica de la metilación (MSP) proporciona información cualitativa del estado de metilación de una secuencia concreta. Esta técnica fue originalmente descrita por Herman y colaboradores en 1996 [18] y desde entonces ha sido predominantemente usada para el análisis de genes supresores de tumores en muestras primarias de pacientes $[19,20]$. La reacción en cadena de la polimerasa específica de la metilación incluye el tratamiento inicial con bisulfito y el uso de dos pares de cebadores específicos, uno para regiones metiladas y otro para las no metiladas, diseñados para discriminar entre las citosinas convertidas y las no convertidas (véase figura 2) [2। ]. Aproximadamente el 0,1\% del ADN metilado puede ser detectado mediante esta técnica, por lo que se considera altamente sensible [ I I]; no obstante, no discrimina entre los niveles bajos y altos de metilación en una secuencia determinada.

\section{A}

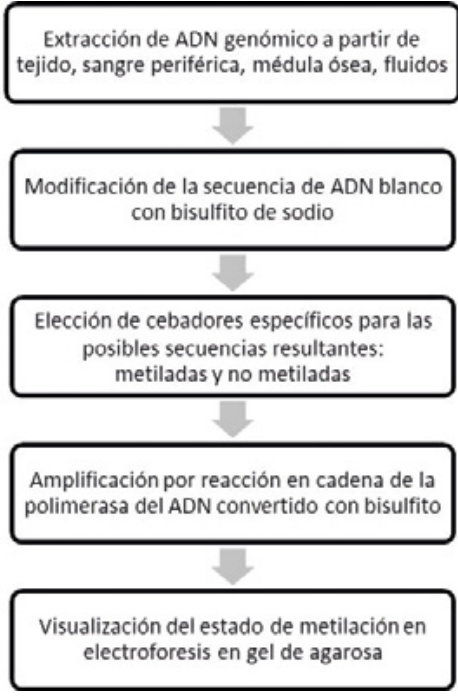

B

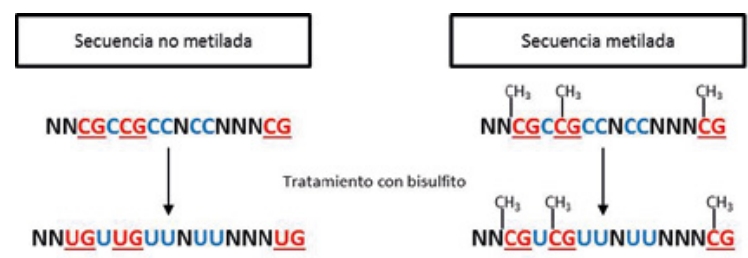

C

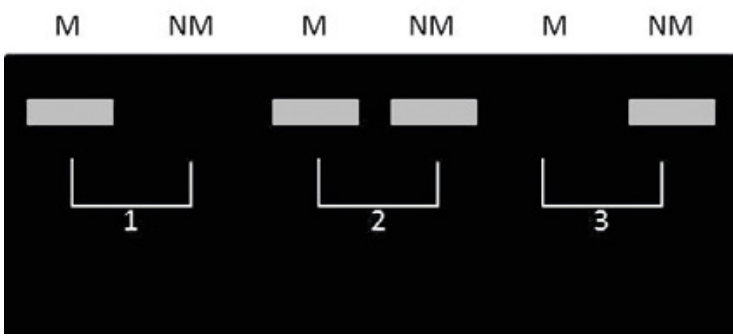

Figura 2. A. Esquema general de la técnica de reacción en cadena de la polimerasa específica de la metilación (MSP). El ADN de las muestras es extraído, modificado con bisulfito de sodio y amplificado con dos pares de cebadores previamente diseñados. El primero reconoce y se une exclusivamente a secuencias metiladas y el segundo reconoce las secuencias que no están metiladas. Finalmente, el estado de la metilación se visualiza en gel de agarosa. B. Efecto de la modificación de bisulfito sobre las secuencias ricas en CpG. Las citosinas no metiladas se convierten en uracilos, mientras que las metiladas no sufren ninguna modificación. C. Representación de los posibles resultados de la MSP visualizados en la electroforesis en gel de agarosa. M: secuencia metilada; NM: secuencia no metilada; I: ADN metilado; 2: ADN hemimetilado; 3: ADN no metilado.

Las desventajas de esta técnica se deben sobre todo a los efectos del bisulfito en el ADN, ya que se ha demostrado que causa una degradación extensa en las secuencias diana y mayores pérdidas en los pasos de purificación, lo que puede afectar el rendimiento del ensayo y la inducción de sesgos en la amplificación [22]. También existe riesgo de arrojar resultados falsos positivos o sobreestimar la metilación de una secuencia dada debido a la conversión incompleta del bisulfito que lleva a que la secuencia sin metilar pueda ser amplificada por el cebador específico de metilación [23]. En contraposición, diferentes casas comerciales han diseñado 
estuches encaminados a la recuperación y purificación del ADN convertido con bisulfito ( $p$. ej. DAPKI, Zymo Research, California, Estados Unidos), y se han implementado técnicas para garantizar la conversión completa del ADN, pero no todos los estudios tienen en cuenta estos aspectos [24].

\section{Utilidad de la reacción en cadena de la polimerasa específica de la metilación en el estudio de las neoplasias hematológicas}

A pesar de sus desventajas, la reacción en cadena de la polimerasa específica de la metilación ha sido utilizada ampliamente en estudios epigenéticos relacionados con neoplasias hematológicas, debido a que es un ensayo sencillo y costo-efectivo [I I ]. La discriminación de genes específicos que están modificados por mecanismos epigenéticos, como la metilación del ADN, ha sido posible gracias al empleo de esta técnica. En la patogénesis de las leucemias el silenciamiento de genes por hipermetilación es frecuente, entre ellos los genes supresores de tumores, genes asociados a apoptosis y genes reguladores del ciclo celular [25].

Gracias a la reacción en cadena de la polimerasa específica de la metilación se han podido realizar diversos estudios encaminados a conocer los eventos biológicos que están presentes en el inicio, la progresión y fenómenos de resistencia en las neoplasias hematológicas; además, se ha facilitado la identificación de biomarcadores que pueden tener un valor pronóstico y, mejor aún, brindar la posibilidad de realizar una terapia personalizada y dirigida [7,26-30]. Algunos genes hipermetilados relacionados con neoplasias hematológicas que han sido identificados utilizando esta técnica se describen en la tabla 1.

\section{Análisis combinado de restricción bisulfito}

El análisis combinado de restricción bisulfito (COBRA; del inglés, combined bisulfite restriction analysis) es una técnica cuantitativa que determina el nivel de metilación de un gen específico en pequeñas cantidades de ADN genómico. Este método se compone básicamente de los siguientes pasos: una reacción en cadena de la polimerasa estándar después del tratamiento con bisulfito de sodio, la digestión con enzimas de restricción y la cuantificación de la metilación de la secuencia determinada [39].

Xiong y colaboradores describieron esta técnica, en la que se incluye inicialmente la conversión de las citosinas no metiladas en uracilos para la posterior amplificación por reacción en cadena de la polimerasa. Previamente, se realiza el diseño de unos cebadores que sean complementarios con la secuencia de ADN convertido y no contengan dinucleótidos CpG en la región correspondiente del ADN original sin convertir, esto produce que durante la amplificación no se discrimine entre los ADN molde según su estado de metilación [40].

Antes de iniciar la digestión, los productos de la reacción en cadena de la polimerasa son purificados y luego digeridos con una enzima de restricción que tiene un sitio de reconocimiento CpG en la secuencia de ADN original sin convertir. De esta manera, el corte sólo ocurre si la secuencia CpG se mantuvo intacta en la conversión con bisulfito, es decir, si sus citosinas se encontraban originalmente metiladas; entretanto, los sitios que se encontraban originalmente no metilados no son cortados [40]. 


\begin{tabular}{|c|c|c|c|}
\hline Genes & $\begin{array}{l}\text { Tipo de neoplasia } \\
\text { hematológica }\end{array}$ & Hallazgo relevante & Referencia \\
\hline pI5, pI6, p53 y DAPK & $\begin{array}{l}\text { Leucemia mieloide crónica } \\
\text { (fase crónica) }\end{array}$ & $\begin{array}{l}\text { Genes del ciclo celular y apoptosis } \\
\text { que se encuentran hipermetilados }\end{array}$ & $\begin{array}{l}\text { Bodoor y cols., } \\
2014[26]\end{array}$ \\
\hline pI6INK4a & $\begin{array}{l}\text { Leucemia mieloide crónica } \\
\text { (fase crónica, acelerada y } \\
\text { blástica) }\end{array}$ & $\begin{array}{l}\text { Implicado en la progresión de fase } \\
\text { clínica }\end{array}$ & $\begin{array}{l}\text { Ahmad y cols., } \\
2014[27]\end{array}$ \\
\hline SHP-I & $\begin{array}{l}\text { Leucemia mieloide crónica } \\
\text { (fase acelerada y blástica) }\end{array}$ & $\begin{array}{l}\text { Implicado en la progresión de fase } \\
\text { clínica }\end{array}$ & $\begin{array}{l}\text { Li y cols., } 2014 \\
{[28]}\end{array}$ \\
\hline $\begin{array}{l}\text { PI5, MGMT,RAR } \boldsymbol{\beta} \\
\text { pI6,DAPK y FHIT }\end{array}$ & $\begin{array}{l}\text { Leucemia mieloide crónica } \\
\text { (fase blástica) }\end{array}$ & $\begin{array}{l}\text { Implicados en la progresión de fase } \\
\text { clínica }\end{array}$ & $\begin{array}{l}\text { Uehara y cols., } \\
2012[6]\end{array}$ \\
\hline BIM & Leucemia mieloide crónica & $\begin{array}{l}\text { Relacionado con respuesta reducida } \\
\text { al tratamiento con Imatinib }\end{array}$ & $\begin{array}{l}\text { San Jose y cols., } \\
2009 \text { [29] }\end{array}$ \\
\hline $\begin{array}{l}\text { MLHI, RPRM, } \\
\text { FEMIB y THAP2 }\end{array}$ & Leucemia mieloide crónica & $\begin{array}{l}\text { Potenciales biomarcadores de resis- } \\
\text { tencia al Imatinib }\end{array}$ & $\begin{array}{l}\text { You y cols., } 2012 \\
{[7]}\end{array}$ \\
\hline GRAF & Leucemia mieloide aguda & $\begin{array}{l}\text { Gen hipermetilado que podría ser un } \\
\text { evento temprano en esta leucemia }\end{array}$ & $\begin{array}{l}\text { Qian y cols., } \\
2011 \text { [30] }\end{array}$ \\
\hline MEG3 & Leucemia mieloide aguda & $\begin{array}{l}\text { Hipermetilación del gen asociada con } \\
\text { mal pronóstico }\end{array}$ & $\begin{array}{l}\text { Benetatos y cols., } \\
2010[31]\end{array}$ \\
\hline pl5 & Leucemia mieloide aguda & $\begin{array}{l}\text { Potencial biomarcador en esta } \\
\text { leucemia }\end{array}$ & $\begin{array}{l}\text { Bodoor y cols., } \\
2014[26]\end{array}$ \\
\hline $\mathrm{C} / \mathrm{EBP} \zeta$ & Leucemia mieloide aguda & $\begin{array}{l}\text { Hipermetilación y baja expresión del } \\
\text { gen }\end{array}$ & $\begin{array}{l}\text { Yao y cols., 20 I I } \\
\text { [32] }\end{array}$ \\
\hline TSC2 & Leucemia mieloide aguda & $\begin{array}{l}\text { Hipermetilación del promotor asocia- } \\
\text { da con baja expresión de la proteína } \\
\text { TSC2 que participa en el ciclo celular }\end{array}$ & $\begin{array}{l}\text { Xu y cols., } 2009 \\
\text { [33] }\end{array}$ \\
\hline SFRPI y SFRP2 & Leucemia mieloide aguda & $\begin{array}{l}\text { Posiblemente involucrados en la ini- } \\
\text { ciación de la enfermedad (detectadas } \\
\text { en pacientes con diagnóstico de novo) }\end{array}$ & $\begin{array}{l}\text { Ghasemi y cols., } \\
2015 \text { [34] }\end{array}$ \\
\hline MT3 & Leucemia mieloide aguda & $\begin{array}{l}\text { Gen inactivado en pacientes pediá- } \\
\text { tricos }\end{array}$ & $\begin{array}{l}\text { Tao y cols., } 2014 \\
{[35]}\end{array}$ \\
\hline DAPK & Leucemia linfoide crónica & $\begin{array}{l}\text { Potencial biomarcador de esta } \\
\text { leucemia }\end{array}$ & $\begin{array}{l}\text { Bodoor y cols., } \\
2014[26]\end{array}$ \\
\hline CALCA & Leucemia linfoide crónica & $\begin{array}{l}\text { Asociado con pacientes de alto riesgo } \\
\text { de infiltración a sistema nervioso } \\
\text { central }\end{array}$ & $\begin{array}{l}\text { Paixao y cols., } \\
2006[36]\end{array}$ \\
\hline $\begin{array}{l}\text { DLCI,SHP-I,pl5, } \\
\text { pl6 }\end{array}$ & Leucemia linfoide crónica & $\begin{array}{l}\text { Relacionados con un estado de diag- } \\
\text { nóstico avanzado }\end{array}$ & $\begin{array}{l}\text { Forsterova y } \\
\text { cols., } 2010[37]\end{array}$ \\
\hline$p|5, p| 6, p 53$ & Leucemia linfoide aguda & $\begin{array}{l}\text { Genes del ciclo celular y apoptosis } \\
\text { que se encuentran hipermetilados }\end{array}$ & $\begin{array}{l}\text { Bodoor y cols., } \\
2014[26]\end{array}$ \\
\hline PTEN & $\begin{array}{l}\text { Leucemia linfoide aguda (con } \\
\text { cromosoma Filadelfia positivo) }\end{array}$ & $\begin{array}{l}\text { Relacionada con la resistencia al Imati- } \\
\text { nib en pacientes con Filadelfia positivo }\end{array}$ & $\begin{array}{l}\text { Montiel-Duarte } \\
\text { y cols., } 2008 \text { [38] }\end{array}$ \\
\hline
\end{tabular}

La eficiencia de la digestión puede ser verificada con el empleo de un control de digestión, utilizando por ejemplo una enzima con secuencia de reconocimiento CATG, que no debe permanecer después de la conversión con bisulfito. Por lo tanto, si se produce algún clivaje indica que no hubo metilación del ADN o que se presentó una conversión incompleta con el bisulfito. Finalmente, los productos de las digestiones son separados en gel de poliacrilamida desnaturalizado y transferidos 
a una membrana por electroblotting para luego ser hibridados con oligonucleótidos y cuantificados por una fosforimagen [40] (véase figuras 3 y 4 ).

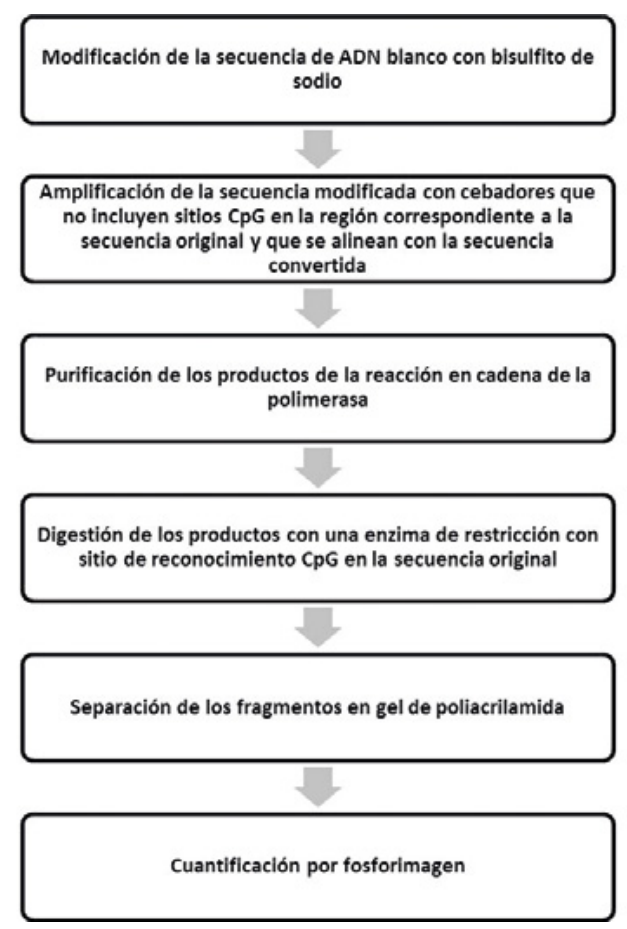

Figura 3. Esquema general sobre la técnica COBRA descrita por Xiong y colaboradores (1997) [40].

El análisis combinado de restricción bisulfito es comúnmente usado para la determinación del estado de metilación de un gran conjunto de muestras, es técnicamente simple y, dependiendo de la región que está siendo investigada, puede brindar información sobre el estado de metilación de varios sitios CpG de la secuencia en una sola reacción [4I]. Aunque, cabe señalar que sólo proporciona información sobre el estado de metilación de ADN de los sitios CpG que son parte del sitio de reconocimiento de la enzima de restricción.

Este método, basado en la electroforesis en gel, tiene varios inconvenientes: consume mucho tiempo, requiere una gran cantidad de muestra y presenta un poder de separación limitada [42]. Además, el sistema amplifica todo el ADN, es decir, no hay una amplificación preferencial del ADN metilado, por lo que las muestras que contenían originalmente sólo trazas de ADN metilado lo presentan de igual forma en el producto de la reacción en cadena de la polimerasa. Estas pequeñas cantidades no se pueden detectar fácilmente a través de la restricción enzimática [43].

Además de esto, el principal inconveniente del análisis combinado de restricción bisulfito es que la información cuantitativa no se puede extraer fácilmente a partir del ensayo. Los intentos para cuantificar el ADN metilado se han realizado mediante hibridación de los productos de restricción con cebadores marcados radiactivamente. Aunque se han obtenido resultados 


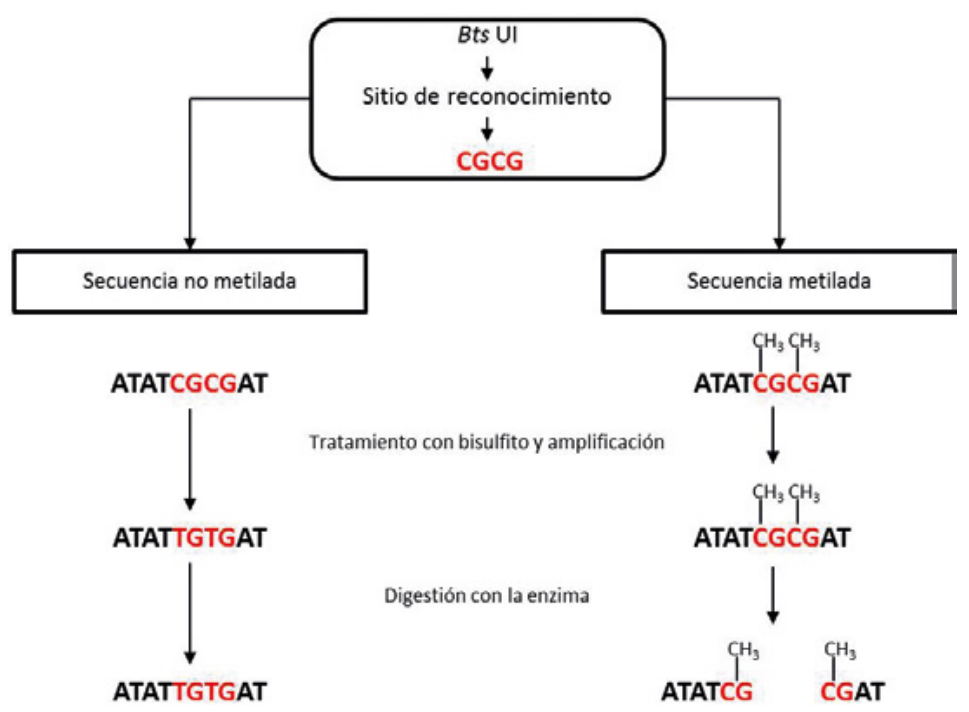

B

Muestra $1 \quad$ Muestra 2

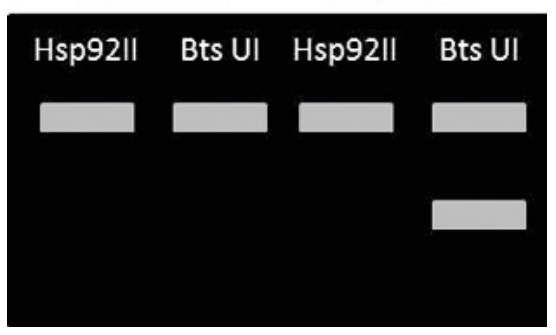

Figura 4. A. Esquema de acción de la enzima de restricción Bts $\mathrm{UI}$ en las secuencias metiladas y no metiladas. El sitio de reconocimiento de la enzima es la secuencia CGCG. Cuando una secuencia de ADN no metilada es sometida al tratamiento con bisulfito y luego amplificada, las citosinas son convertidas a timinas, lo que produce la pérdida del sitio de reconocimiento de la enzima y, en consecuencia, evita que la secuencia sea cortada, permaneciendo intacta. Cuando una secuencia metilada es sometida al mismo procedimiento, las citosinas metiladas no son modificadas por el bisulfito y, por tanto, la enzima está en la capacidad de reconocer y cortar la secuencia. B. Representación de la visualización en gel de poliacrilamida del control negativo y de muestras con o sin metilación. En el ensayo debe incluirse un control de digestión con una enzima de restricción como la Hsp92II, cuya secuencia de reconocimiento es CATG, que debe ser destruida por la conversión del bisulfito. Cualquier escisión por la Hsp92Il indica una conversión incompleta del bisulfito de sodio. Muestra I: sin metilación; muestra 2: 100\% metilada. Obsérvese la presencia de dos bandas correspondientes a los dos fragmentos formados por la escisión de la enzima Bts UI.

exitosos bajo este enfoque, el método es laborioso e implica el uso de un isotopo radioactivo. De igual manera, se ha intentado cuantificar las intensidades de los fragmentos de ADN teñidos con bromuro de etidio usando programas informáticos de edición de imágenes. El problema de este enfoque es la subestimación de las señales fuertes; además, la fluorescencia del fondo de las imágenes del gel es con frecuencia variable lo que afecta los cálculos y hace imposible comparar de forma confiable los niveles de metilación en las muestras [4I].

Por tal razón, se han realizado modificaciones de la técnica con el propósito de realizar una cuantificación precisa y reproducible del ADN metilado, como la combinación del análisis combinado de restricción bisulfito y la electroforesis capilar con fluorescencia inducida por láser (CE-LIF; del inglés, capillary electrophoresis with laser induced fluorescence detection) [42] y el Bio-COBRA, que combina el sistema original con la plataforma del bioanalizador Agilent 2100 (Agilent Technologies, Inc., California, Estados Unidos) [4I]. Estas técnicas modificadas ofrecen ciertas ventajas como una buena separación, eficiencia, alta sensibilidad y cuantificación de pe- 
queños tamaños de muestra, lo cual convierte al análisis combinado de restricción bisulfito en una importante herramienta para el desarrollo de parámetros diagnósticos y pronósticos para la detección y manejo de las enfermedades.

\section{Utilidad del análisis combinado de restricción bisulfito en el estudio de las neoplasias hematológicas}

El análisis combinado de restricción bisulfito ha permitido conocer con más de detalle los niveles de metilación de los genes involucrados en el comienzo, la progresión y la resistencia al tratamiento en las neoplasias hematológicas, debido a su carácter cuantitativo y la capacidad de realizarse en gran cantidad de muestras. Algunos genes hipermetilados relacionados con neoplasias hematológicas que han sido identificados utilizando esta técnica se describen en la tabla 2.

\begin{tabular}{|c|c|c|c|}
\hline Genes & $\begin{array}{l}\text { Tipo de neoplasia } \\
\text { hematológica }\end{array}$ & Hallazgo relevante & Referencia \\
\hline hMSH2 & Leucemia linfoide aguda & $\begin{array}{l}\text { El incremento de la metilación de este gen } \\
\text { disminuye la supervivencia en los pacientes } \\
\text { con leucemia linfoide aguda }\end{array}$ & Wang y cols., 2014 [44] \\
\hline $\begin{array}{l}\text { RASSF6 } \\
\text { y RASSFI0 }\end{array}$ & Leucemia linfoide aguda & $\begin{array}{l}\text { El perfil de hipermetilación de este gen es } \\
\text { diferente al de los tumores sólidos. Estos } \\
\text { son frecuentes en la patogénesis de la } \\
\text { leucemia linfoide aguda }\end{array}$ & Hesson y cols., 2009 [45] \\
\hline TWIST2 & Leucemia linfoide aguda & $\begin{array}{l}\text { La inactivación epigenética tiene un rol } \\
\text { dual en el pronóstico de la enfermedad y } \\
\text { la resistencia a quimioterapia }\end{array}$ & Thathia y cols., 20 I I [46] \\
\hline HOXA5 & $\begin{array}{l}\text { Leucemia mieloide } \\
\text { crónica }\end{array}$ & $\begin{array}{l}\text { La hipermetilación del gen está fuertemente } \\
\text { correlacionada con la progresión a fase } \\
\text { blástica }\end{array}$ & Strathdee y cols., 2007 [47] \\
\hline TTCI2 & Leucemia linfoide aguda & $\begin{array}{l}\text { La expresión es inhibida en asociación con } \\
\text { la hipermetilación del gen }\end{array}$ & $\begin{array}{l}\text { Wattanawaraporn y } \\
\text { cols., } 2007 \text { [48] }\end{array}$ \\
\hline $\begin{array}{l}\text { CD38 } \\
\text { y HOXA4 }\end{array}$ & Leucemia linfoide crónica & $\begin{array}{l}\text { Estos marcadores pueden ser usados para } \\
\text { estratificar el riesgo }\end{array}$ & Irving y cols.,201 I [49] \\
\hline
\end{tabular}

Utilizando el análisis combinado de restricción bisulfito se pudo determinar en I I 8 pacientes con leucemia linfoide crónica una puntuación global de la metilación en un panel de genes: CD38, HOXA4 (homeobox A4) y BTG4 (gen 4 de translocación de células B), que tiene un valor predictivo en la progresión de la enfermedad, lo que demuestra que este enfoque permite estratificar el riesgo de un buen o mal curso en los pacientes con leucemia linfoide crónica [49].

Wattanawaraporn y colaboradores ilustraron con más detalle el comportamiento de la metilación del gen TTCI 2 (dominio 12 repetido de tetratricopéptido) de los leucocitos de individuos sanos y las médulas óseas de pacientes con remisión completa y con leucemia linfoide aguda, en los que pudieron determinar las medias estadísticas y los niveles más altos de metilación, siendo mayores en el último grupo, lo que demuestra la asociación entre la regulación epigenética y la leucemia linfoide aguda [48]. 


\section{Técnicas de secuenciación en el análisis de metilación del ADN}

El análisis de todos los dinucleotidos CpG en una secuencia dada permite tener una visión más amplia de los niveles de metilación del ADN. Cambios en muy pocos o incluso en un solo dinucleotido CpG son suficientes para alterar la expresión de un gen. Esto ha sido posible verificarlo gracias al análisis de metilación cuantitativa en los promotores de genes susceptibles de ser estudiados. En la actualidad los métodos más utilizados para la cuantificación de la metilación en una región específica son: la secuenciación con bisulfito y la pirosecuenciación [50].

\section{Secuenciación dependiente de bisulfito de sodio}

La secuenciación con bisulfito (BSP; del inglés, bisulfite sequencing PCR) es el estándar de oro para el mapeo de la metilación alelo específica en los sitios CpG de los productos de la reacción en cadena de la polimerasa luego de la conversión con bisulfito de sodio. Casi todas las investigaciones que estudian la metilación del ADN dependen directa o indirectamente de los datos obtenidos para la región de interés arrojados por la secuenciación con bisulfito de sodio [5 I].

Esta técnica consiste en la conversión del ADN con bisulfito de sodio, seguido de la amplificación de una región de interés mediante reacción en cadena de la polimerasa y, finalmente, la secuenciación del producto de amplificación de forma directa o posterior a la clonación en un vector adecuado [24] (véase figura 5).

Tradicionalmente, la secuenciación con bisulfito basada en clonación es la más comúnmente utilizada, además es la primera técnica descrita para el análisis de metilación utilizando la reacción en cadena de la polimerasa. Con este método se realiza inicialmente una reacción de conversión con bisulfito de sodio seguido del proceso de desnaturalización, amplificación y clonación. Después de la expansión y purificación de los plásmidos, los productos de inserción de la reacción en cadena de la polimerasa son secuenciados. El estado de metilación de cada CpG en la región de interés es determinado por la secuencia de cada clon expandido [52,53]. Para obtener una mayor sensibilidad se requiere de seis reacciones de secuenciación.

Una de las ventajas de esta técnica es que es la única opción para la determinación de la metilación de haplotipos en el laboratorio [54]; sin embargo, presenta varios inconvenientes debido a que tiene múltiples pasos laboriosos (p. ej. el tratamiento con bisulfito, la clonación de los fragmentos de la reacción en cadena de la polimerasa, la construcción de vectores recombinantes, la identificación de clones positivos y la secuenciación del ADN), lo que implica una mano de obra intensiva y capacitada, y mucho tiempo de procesamiento, lo cual es inadecuado para el análisis de muestras de alto rendimiento [50]. Además, existen evidencias de que los amplicones con citosinas pueden ser más difíciles de clonar eficientemente [55].

La secuenciación con bisulfito directa, es decir, sin realizar la clonación previa, provee información sobre el estado de metilación promedio para cada CpG mediante la comparación de los resultados de la región de interés con una secuencia de referencia del ADN genómico respectivo. Este método constituye una forma corta, más rápida y menos dispendiosa de realizar la secuenciación [24]. Algunos inconvenientes de este tipo de análisis son la mala calidad de la señal debido a la sobredimensión de citosinas causada por artefactos que afectan el análisis 

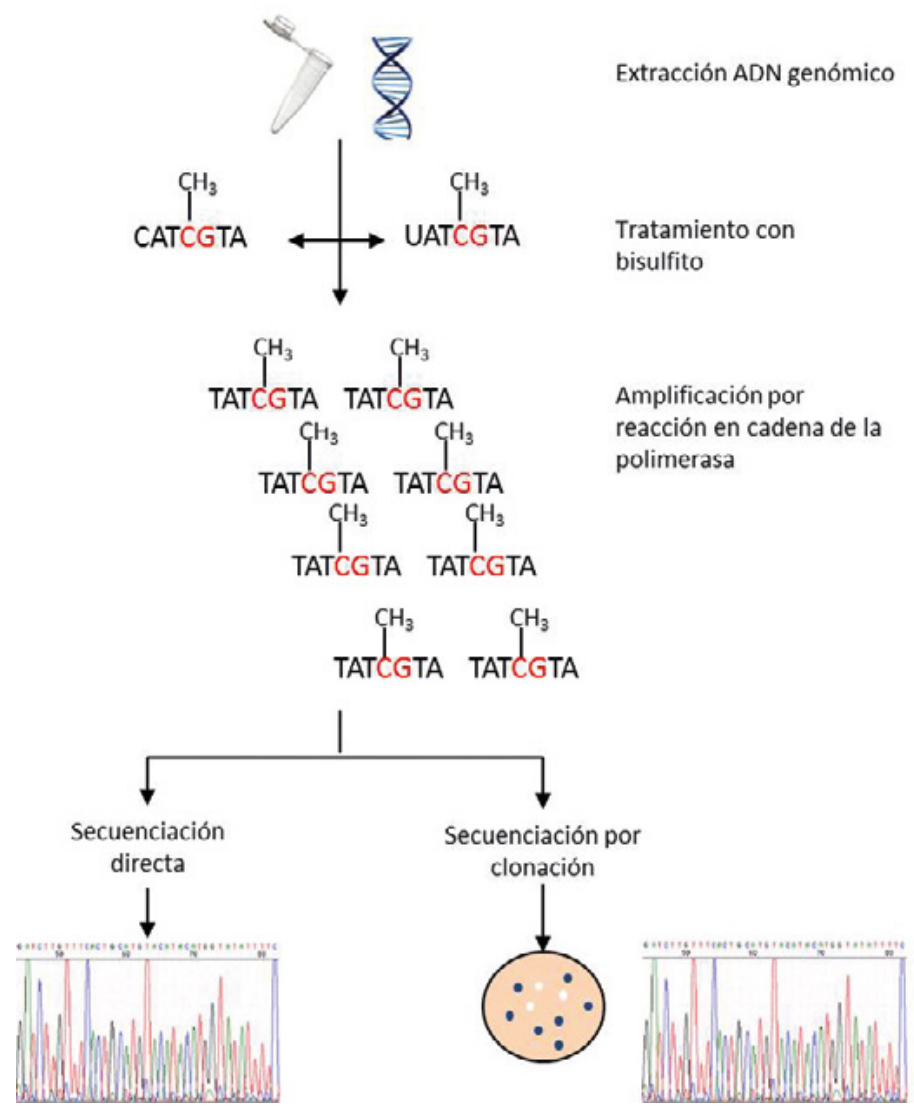

Figura 5. Esquema general de la secuenciación con bisulfito directa y por clonación. Inicialmente se realiza la extracción del ADN genómico para ser convertido con bisulfito, amplificado por la reacción en cadena de la polimerasa y secuenciado de forma directa o luego de un paso previo de clonación.

del electroferograma y las señales brindadas por la conversión incompleta con el bisulfito. A pesar de esto, la secuenciación con bisulfito brinda una información del estado de metilación a lo largo de las hebras de ADN individuales, donde por ejemplo los patrones bimodales de metilación son claramente evidentes. Además, requiere de poco conocimiento técnico y se puede realizar utilizando estuches disponibles comercialmente [56].

\section{Pirosecuenciación con bisulfito}

Colella y colaboradores desarrollaron, en 2003, un método altamente cuantitativo para evaluar el nivel de metilación en sitios específicos utilizando la tecnología de pirosecuenciación. Los análisis de metilación por pirosecuenciación ("PyroMethA") son una modificación del análisis combinado de restricción bisulfito, en el que el análisis de restricción es sustituido por una reacción de pirosecuenciación altamente cuantitativa [57].

La pirosecuenciación es un método de secuenciación por síntesis que monitorea cuantitativamente la incorporación en tiempo real de los nucleótidos mediante la conversión enzimática del pirofosfato liberado en una señal de luz proporcional. Este método combina un protocolo 
de reacción simple con medidas reproducibles y precisas del grado de metilación en varias CpG con una alta resolución cuantitativa. Después del tratamiento con bisulfito de sodio y la amplificación mediante reacción en cadena de la polimerasa, el grado de cada metilación en cada posición de CpG en una secuencia se determina a partir de la relación de timina y citosina [58](véase figura 6).

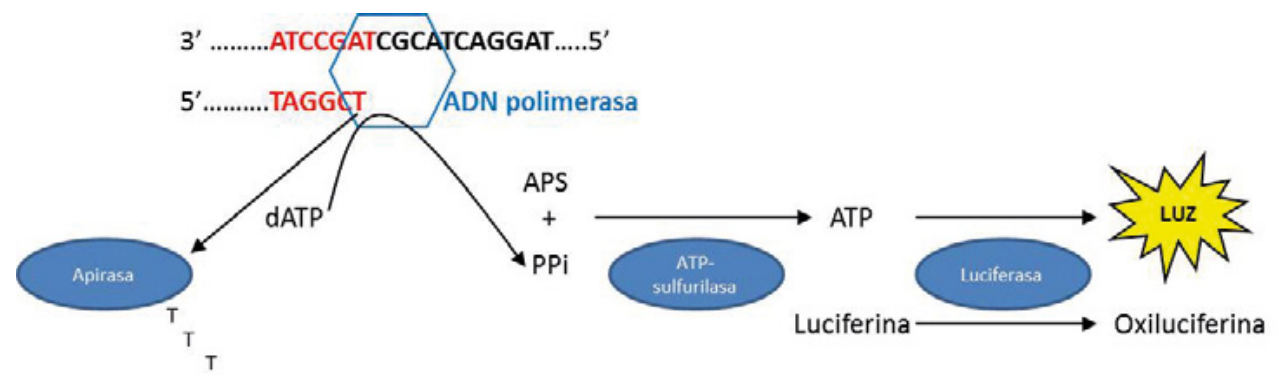

Figura 6. Esquema general de la pirosecuenciación. El proceso inicia con la incorporación de uno de los cuatro deoxiribonuclotidos (dNTPs), si este es complementario a la hebra molde la ADN polimerasa cataliza la incorporación y libera pirofosfato (PPi). Utilizando APS (adenosina 5'-fosfosulfato) como sustrato la ATP-sulforilasa convierte cuantitativamente el pirofosfato recién liberado en ATP (adenosín trifosfato), lo que activa la conversión de la luciferina a oxiluciferina por la acción de la luciferasa. Esta reacción genera una señal de luz proporcional a la cantidad de ATP producido. Un equipo capta la señal y genera un picograma, el cual muestra picos representando los nucleótidos incorporados. La apirasa degrada los dNTPs que no son incorporados.

Este método tiene como ventaja la inclusión de un control interno, el cual corresponde a una secuencia de ADN que contiene citosinas no convertidas, lo que permite la cuantificación precisa de varios sitos CpG en una sola reacción. Uno de los inconvenientes que se presentan es que sólo pueden ser secuenciados en cada reacción 20 a 30 pares de bases, lo que limita el número de CpG que pueden ser evaluadas [39].

\section{Utilidad de las técnicas de secuenciación en el estudio de las neoplasias hematológicas}

La secuenciación con bisulfito es una técnica ampliamente utilizada en el análisis de metilación de genes en las neoplasias hematológicas ya que es considerado el estándar de oro en los estudios epigenéticos. Esta técnica ha sido útil en la detección de potenciales biomarcadores que lideran los procesos de transformación, progresión y resistencia de los cánceres hematológicos. Por su parte, la pirosecuenciación ha permitido la cuantificación fidedigna del estado de metilación en los mismos procesos, lo que ha permitido realizar estratificaciones de riesgo de recaída, resistencia y enfermedad residual, que posibilitan realizar un pronóstico en los pacientes con este tipo de enfermedades. Algunos genes hipermetilados relacionados con las neoplasias hematológicas que han sido identificados utilizando estas técnicas se describen en la tabla 3.

En los estudios de metilación de genes implicados en las neoplasias hematológicas usualmente la secuenciación con bisulfito y la pirosecuenciación son empleadas de manera simultánea o concomitantemente con otras técnicas. Bohne y colaboradores utilizaron la secuenciación y la pirosecuenciación para identificar y asociar la modulación epigenética de la hipermetilación del gen ERG (gen 


\begin{tabular}{|c|c|c|c|}
\hline Genes & $\begin{array}{l}\text { Tipo de neoplasia } \\
\text { hematológica }\end{array}$ & Hallazgo relevante & Referencia \\
\hline \multirow[t]{2}{*}{ HOXA5 } & Leucemia mieloide aguda & $\begin{array}{l}\text { La cuantificación de la metilación } \\
\text { de HOXA5 por pirosecuenciación } \\
\text { es útil para predecir el pronóstico } \\
\text { a corto plazo en la leucemia mie- } \\
\text { loide aguda }\end{array}$ & Kim y cols., 2010 [59] \\
\hline & Leucemia mieloide crónica & $\begin{array}{l}\text { La hipermetilación de este gen está } \\
\text { fuertemente correlacionada con la } \\
\text { progresión a fase blástica, y ha sido } \\
\text { determinado por secuenciación } \\
\text { con bisulfito }\end{array}$ & Strathdee y cols., 2007 [47] \\
\hline Ligandos NKG2D & Leucemia mieloide aguda & $\begin{array}{l}\text { La hipermetilación de los ligandos } \\
\text { de NKG2D ha sido determinada } \\
\text { por pirosecuenciación y se ha } \\
\text { demostrado que contribuyen a la } \\
\text { evasión del sistema inmune de las } \\
\text { células tumorales en la leucemia } \\
\text { mieloide aguda }\end{array}$ & $\begin{array}{l}\text { Baragaño Raneros y cols., } \\
2015 \text { [60] }\end{array}$ \\
\hline MT3 & Leucemia mieloide aguda & $\begin{array}{l}\text { Este gen es inactivado en los pa- } \\
\text { cientes pediátricos. El estado de } \\
\text { metilación ha sido determinado por } \\
\text { secuenciación con bisulfito }\end{array}$ & Tao y cols., $20 \mid 4$ [35] \\
\hline CASP8AP2 & Leucemia linfoide aguda & $\begin{array}{l}\text { El análisis del estado de metilación } \\
\text { de este gen ha sido realizada por } \\
\text { secuenciación de bisulfito, la cual } \\
\text { mostró hipermetilación asociada } \\
\text { con enfermedad mínima residual } \\
\text { (MRD) y respuesta pobre al tra- } \\
\text { tamiento }\end{array}$ & Li y cols., 2013 [6I] \\
\hline ERG & $\begin{array}{l}\text { Leucemia linfoide aguda } \\
\text { de células } T\end{array}$ & $\begin{array}{l}\text { Este gen es importante en la di- } \\
\text { ferenciación hematopoyética. Se } \\
\text { encuentra hipermetilado según } \\
\text { los análisis por secuenciación con } \\
\text { bisulfito }\end{array}$ & Bohne y cols., 2009[62] \\
\hline $\mathrm{BIM}$ & Leucemia mieloide crónica & $\begin{array}{l}\text { La baja regulación de BIM es epi- } \\
\text { genéticamente controlada por } \\
\text { hipermetilación en pacientes con } \\
\text { leucemia mieloide crónica y tienen } \\
\text { un impacto desfavorable en el } \\
\text { pronóstico. La hipermetilación de } \\
\text { este gen ha sido determinada por } \\
\text { secuenciación con bisulfito }\end{array}$ & San Jose-Eneriz y cols., 2009 [29] \\
\hline hMSH2 & Leucemia linfoide aguda & $\begin{array}{l}\text { El incremento de la metilación } \\
\text { disminuye la supervivencia en los } \\
\text { pacientes con leucemia linfoide agu- } \\
\text { da. La cuantificación de la metilación } \\
\text { se realizó por pirosecuenciación }\end{array}$ & Wang y cols., $20 \mid 4$ [44] \\
\hline
\end{tabular}

relacionado con eritroblastos de transformación específicos) con la leucemia linfoide aguda de células T [62]. Por su parte, Tao y colaboradores determinaron el estado de hipermetilación del gen MT3 (metalotioneina 3) mediante el uso de la reacción en cadena de la polimerasa específica de la metilación y la secuenciación con bisulfito en niños que padecen leucemia mieloide aguda [35]. Wang y colaboradores, utilizando simultáneamente dos técnicas cuantitativas, el análisis combinado de restricción bisulfito y la pirosecuenciación, demostraron la implicación 
del gen hMSH2 (homólogo en humanos-2 de mutS) en el desarrollo de la leucemia linfoide aguda y en la supervivencia de estos pacientes [44].

Otra de las aplicaciones actuales de las técnicas de secuenciación con bisulfito es la nueva generación de secuencias de metilomas que proveen perfiles digitales individuales para cánceres humanos, que podrían potencialmente proveer un método robusto para la clasificación epigenética de los subtipos de tumores. Por ejemplo, Queiros y colaboradores, utilizando cinco biomarcadores epigenéticos lograron clasificar a los pacientes con leucemia linfoide crónica de células $B$ en los tres subtipos clínicos-biológicos (de células inmaduras, intermedias y maduras tipo B) [63].

\section{Técnicas para análisis de metilación basadas en micromatrices}

Las micromatrices (del inglés, microarrays) para el análisis de metilación son técnicas moleculares ampliamente usadas para determinar el estado de metilación de múltiples genes de forma simultánea. Estas técnicas se basan fundamentalmente en un proceso de hibridación. El sistema consiste en soportes sólidos de cristal o plástico en los que se encuentran dispuestas diferentes sondas específicas de ADN que pertenecen a genes determinados. El ADN tiene la propiedad física de hibridar con secuencias complementarias según ciertas condiciones de temperatura y $\mathrm{pH}$. De esta forma, si en una muestra biológica se encuentra la secuencia complementaria a la sonda de la micromatriz estas hibridan y se pueden visualizar con un trazador, generalmente un fluorocromo. Luego, la micromatriz se escanea y se obtiene la imagen que será analizada en un programa informático especializado [64].

En los últimos años ha existido un aumento creciente en el uso de la tecnología de micromatrices en la metilación y diversos métodos han sido diseñados para obtener una mayor cobertura en el estudio de los cambios de metilación en todo el epigenoma y en genes específicos con el objetivo de mejorar la comprensión de las neoplasias hematológicas [65]. El estuche Illuminna HumanMethylation450 Bead Chip (Illumina, Inc., California, Estados Unidos) es una de las plataformas de micromatrices mejor comprendidas y actualmente disponibles, que debido al alto costo de las tecnologías de secuenciación de próxima generación es ampliamente usada como una herramienta para el análisis de los niveles de metilación en todo el genoma. Esta tecnología permite una alta resolución en los perfiles de metilación del genoma humano ya que cubre el 99\% de genes de secuencia referenciados y aproximadamente 250.000 islas CpG. Esta plataforma está centrada en los promotores de genes y las regiones intergénicas, pero también contiene sitios de interés adicional como las regiones sensibles a DNAsas y los potenciadores. En comparación con los enfoques de secuenciación, las matrices de metilación son una alternativa de bajo costo que permiten el perfilado de un gran número de muestras, aunque con una resolución reducida [66].

Otra técnica de metilación basada en micromatrices es el sistema Epitect Methyl II PCR Array (Qiagen N.V., Venlo, Países Bajos), la cual utiliza la tecnología MethylScreen, que se basa en la escisión diferencial de secuencias diana por dos enzimas de restricción cuya actividad depende de la presencia o ausencia de citosinas metiladas en el sitio de reconocimiento. Después de la digestión con estas enzimas se cuantifica, por reacción en cadena de la polimerasa en tiempo 
real, la cantidad de ADN restante en cada reacción enzimática. Esto permite calcular de forma fiable y sencilla el estado de metilación de genes individuales (véase figura 7) [67]. Este método es relativamente simple y requiere poco ADN, pero como todas las técnicas que utilizan enzimas de restricción la detección de la isla CpG depende de si la enzima de restricción reconoce los sitios analizados y la digestión incompleta produce falsos positivos [13].

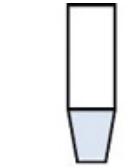

Extracción de ADN
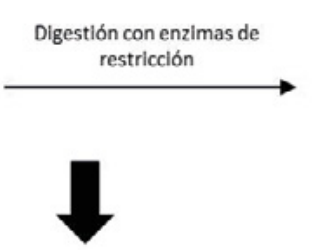

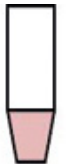

Mo

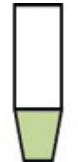

Ms

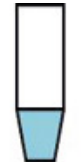

Md

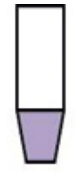

Msd
Mezclado de digestiones de ADN con reacción en cadena de la polimerasa RT2 SYBR Green qPCR, y dispensación de la mezcla en la micromatriz

\section{Control Ms}

Control Md

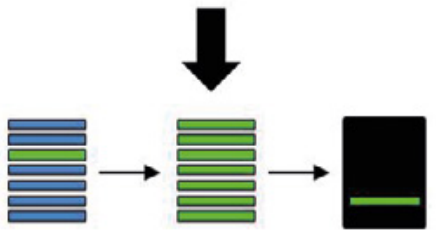

Corrida PCR en tiempo real

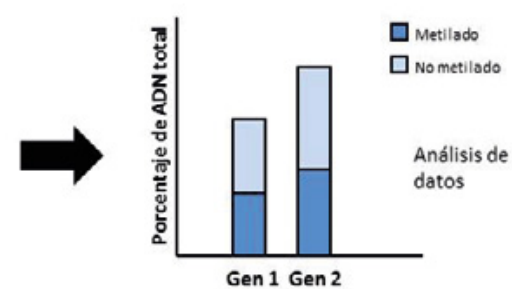

Figura 7. Esquema del estuche EpiTect Methyl II PCR Array. El ADN genómico extraído se somete a cuatro reacciones en tubos separados, en los cuales se adicionan la solución tampón y la combinación de enzimas de restricción apropiada. En el primer tubo se realiza una digestión simulada (Mo) en la que se agrega la solución tampón, pero no se incluyen las enzimas. En el segundo y tercer tubo se llevan a cabo las digestiones enzimáticas, uno empleando una enzima de restricción sensible a la metilación Hhal (Ms) y el otro una enzima dependiente de la metilación McrBC (Md), los cuales determinarán la posterior detección de la fracción metilada y no metilada del ADN, respectivamente. Luego, las mezclas Ms y Md son adicionadas en una cuarto tubo de digestión (Msd). El producto de cada una de las digestiones es mezclado con el estuche $\mathrm{RT}^{2}$ SYBR Green qPCR Mastermix y es dispensado en el plato que contiene dicho panel y donde previamente se depositaron los cebadores específicos para los genes. Posteriormente, se procede a realizar la corrida de la reacción en cadena de la polimerasa en tiempo real basada en inmunoflorescencia y, finalmente, se establece el porcentaje de metilación de los promotores de los genes estudiados. Tomada y modificada de "EpiTect Methyl II PCR Array System: A simple tool for screening regional DNA methylation of a large number of genes or samples without bisulfite conversión" por Jiang y colaboradores, 2012, p. 3. Copyright ${ }^{\odot} 2012$ por QIAGEN.

Los microarreglos pese a ser una tecnología novedosa y efectiva, presentan algunas limitaciones que los hace inadecuados en algunas configuraciones experimentales; por ejemplo, parámetros como la influencia de las variaciones de la secuencia en el ADN, las condiciones de amplificación y la sensibilidad en los métodos no han sido ampliamente investigados [68]. Además, cada vez se encuentra disponible esta tecnología en laboratorios no especializados, por lo que existe una creciente necesidad de herramientas informáticas de fácil uso que permitan la manipulación 
y análisis de un conjunto grande de datos de metilación [69], al igual que sistemas de validación de estos métodos respecto a los estándares de oro mediante la creación de un manual de buenas prácticas entre los investigadores, que asegure que los datos obtenidos son de la mayor calidad posible [65].

\section{Utilidad de las técnicas basadas en micromatrices en el estudio de neoplasias hematológicas}

La tecnología de micromatrices puede ayudar a identificar la variación interindividual en los patrones de metilación en todo el genoma, permite observar los efectos epigenéticos en la diferenciación celular, las remisiones, las recaídas y la resistencia al tratamiento de las neoplasias hematológicas; además, posibilita estratificar y clasificar los tumores o subtipos de leucemias. Algunos estudios realizados en pacientes con neoplasias hematológicas que han sido identificados utilizando esta técnica se describen en la tabla 4.

\begin{tabular}{|c|c|c|c|}
\hline Estudio realizado & $\begin{array}{l}\text { Tipo de neoplasia } \\
\text { hematológica }\end{array}$ & Hallazgo relevante & Referencia \\
\hline $\begin{array}{l}\text { Análisis de un panel de } \\
22 \text { genes supresores de } \\
\text { tumores }\end{array}$ & $\begin{array}{l}\text { Leucemia mieloide } \\
\text { crónica }\end{array}$ & $\begin{array}{l}\text { Del panel de } 22 \text { genes supre- } \\
\text { sores de tumores se encontró } \\
\text { un único gen hipermetilado, el } \\
\text { SLC5A8, en pacientes recién } \\
\text { diagnosticados }\end{array}$ & Chin y cols., 2014 [70] \\
\hline $\begin{array}{l}\text { Visión global del genoma } \\
\text { (metiloma) }\end{array}$ & Leucemia linfoide aguda & $\begin{array}{l}\text { Los patrones de metilación } \\
\text { en los promotores específicos } \\
\text { permiten identificar diferentes } \\
\text { subtipos de leucemia linfoide } \\
\text { aguda con la translocación que } \\
\text { involucra al gen MLL, lo que tiene } \\
\text { influencia en la clínica y opción } \\
\text { terapéutica }\end{array}$ & Stumpel y cols., 2009 [7I] \\
\hline $\begin{array}{l}\text { Visión global del genoma } \\
\text { (metiloma), evaluación } \\
\text { de } 807 \text { genes e iden- } \\
\text { tificación de } 13 \text { genes } \\
\text { hipermetilados en la vía } \\
\text { TP53 }\end{array}$ & Leucemia linfoide aguda & $\begin{array}{l}\text { El análisis demostró simultánea } \\
\text { y frecuente inactivación de los } \\
\text { genes involucrados en la vía } \\
\text { TP53, que se encuentran rela- } \\
\text { cionados con el pronóstico de } \\
\text { la enfermedad }\end{array}$ & $\begin{array}{l}\text { Vilas-Zorzona y cols., } \\
2011 \text { I [72] }\end{array}$ \\
\hline Análisis de 807 genes & $\begin{array}{l}\text { Leucemia mieloide } \\
\text { aguda }\end{array}$ & $\begin{array}{l}\text { La hipermetilación se encontró } \\
\text { en muestras de leucemia mieloi- } \\
\text { de aguda con riesgo de recaída }\end{array}$ & Wilop y cols., 20I I [73] \\
\hline
\end{tabular}

\section{Conclusiones}

En todo tipo de neoplasia un gran número de genes implicados en las vías celulares fundamentales pueden ser afectados por una ganancia en la metilación (hipermetilación) y por el conducente silenciamiento transcripcional [4]. Los patrones alterados de metilación del ADN pueden servir como biomarcadores para la detección, pronóstico y predicción de la respuesta al tratamiento de diferentes enfermedades. Además, ensayos clínicos con terapias dirigidas epigenéticamente han dado resultados prometedores en el caso de las neoplasias hematopoyéticas [74]. 
Las innumerables aplicaciones clínicas de las pruebas para el análisis de metilación de las islas CpG para cánceres hematológicos son prometedoras; sin embargo, un paso crítico para que estas metodologías puedan utilizarse en el diagnóstico molecular clínico es la decisión sobre cuál método emplear. En primera instancia las pruebas deben basarse en los objetivos del estudio a realizar, la selección y el número de islas CpG en los genes o promotores que se evaluarán en cada muestra; debe anticiparse también la heterogeneidad entre lo que es normal y lo anormal, la calidad de los tejidos, las células o el material de ADN o, si es un archivo de patología, determinar si las sustancias fijadoras podrían afectar el método de elección [16].

En la actualidad existe una gran diversidad de técnicas para el análisis de metilación además de las que han sido expuestas en esta revisión. Otros métodos de detección como el MethyLight [75], la fusión de alta resolución sensible a metilación (MS-HRM; del inglés, methylation-sensitive high-resolution melting) [76], el análisis cuantitativo de alelos metilados (QAMA; del inglés, quantitative analysis of methylated alleles) [77], la extensión de los cebadores del nucleótido simple sensible a la metilación (MS-SNuPE; del inglés, methylation-sensitive single nucleotide primer extension) [78], son algunos ejemplos de los métodos de detección de la metilación del ADN que han sido implementados por diferentes investigadores en el mundo. Por tal razón, se hace necesario realizar comparaciones de las diferentes metodologías que permitan establecer una estandarización de los ensayos y desarrollar paneles específicos de cada tipo de neoplasia hematológica para poder utilizar las técnicas de detección de la metilación del ADN en el diagnóstico y seguimiento de estas enfermedades.

El reto es grande, pero el entendimiento de la información que proporciona cada método y sus ventajas y desventajas pueden encaminar a los investigadores a seleccionar una metodología apropiada según sus necesidades y a aumentar el conocimiento sobre la red epigenética que controla la expresión de proteínas y como estas interactúan para producir la progresión de las neoplasias hematológicas, no sólo para realizar el diagnóstico por el laboratorio sino para diseñar nuevas estrategias terapéuticas que combatan la generación de resistencia a los actuales medicamentos.

\section{Agradecimientos}

Los autores agradecen a Luz Marina Jaramillo y a Laura Medina Gómez por su apoyo en la revisión del manuscrito.

\section{Bibliografía}

I. Ngalamika O, Zhang Y, Yin H, Zhao M, Gershwin ME, Lu Q. Epigenetics, autoimmunity and hematologic malignancies: a comprehensive review. J Autoimmun 2012; 39: 45I-465.

2. Han Y, Ren J, Yu W, Terashima M, Muegge K. Malignant Transformation and Epigenetics. En: Lu Q. Chang CC, Richardson BC, eds. Epigenetics and Dermatology. Boston, Estados Unidos: Academic Press; 2015: 113-135.

3. Ntziachristos P, Mullenders J, Trimarchi T, Ai- fantis I. Mechanisms of epigenetic regulation of leukemia onset and progression. Adv Immunol 2013; 1 17: 1-38.

4. Baer C, Plass C. Aberrant DNA Methylation. En: Caplan MJ, Boron WF, Boulpaep EL, Bradshaw RA, Bylund DB, Carlson BM, et al., eds. Reference Module in Biomedical Sciences. Amsterdam, Paises Bajos: Elsevier B.V.; 2014.

5. Melki JR, Clark SJ. DNA methylation changes in leukaemia. Semin Cancer Biol 2002; 12: 347-357. 
6. Uehara E, Takeuchi S, Yang Y, Fukumoto T, Matsuhashi Y, Tamura T, et al. Aberrant methylation in promoter-associated $\mathrm{CpG}$ islands of multiple genes in chronic myelogenous leukemia blast crisis. Oncol Lett 2012; 3: 190-192.

7. You R-I, Ho C-L, Hung H-M, Hsieh Y-F, Ju J-C, Chao T-Y. Identification of DNA methylation biomarkers in imatinib-resistant chronic myeloid leukemia cells. Genomic Med Biomarkers Health Sci 2012; 4: 12-15.

8. Pehlivan M, Sercan Z, Sercan HO. sFRPI promoter methylation is associated with persistent Philadelphia chromosome in chronic myeloid leukemia. Leuk Res 2009; 33: I062-1067.

9. Nagy E, Beck Z, Kiss A, Csoma E, Telek B, Konya J, et al. Frequent methylation of pI6INK4A and pI4ARF genes implicated in the evolution of chronic myeloid leukaemia from its chronic to accelerated phase. Eur J Cancer 2003; 39: 2298 2305 .

10. Vecchio L, Seke Etet PF, Kipanyula MJ, Krampera M, Nwabo Kamdje AH. Importance of epigenetic changes in cancer etiology, pathogenesis, clinical profiling, and treatment: what can be learned from hematologic malignancies? Biochim Biophys Acta 2013; 1836: 90- 104.

II. Galm O, Herman JG, Baylin SB. The fundamental role of epigenetics in hematopoietic malignancies. Blood Rev 2006; 20: I- I3.

12. French SW, Dawson DW, Miner MD, Doerr JR, Malone CS, Wall R, et al. DNA methylation profiling: a new tool for evaluating hematologic malignancies. Clin Immunol 2002; 103: 217-230.

13. Jorda M, Peinado MA. Methods for DNA methylation analysis and applications in colon cancer Mutat Res 2010; 693: 84-93.

14. Feinberg AP, Vogelstein B. Hypomethylation distinguishes genes of some human cancers from their normal counterparts. Nature 1983; 301: 89 . 92.

I5. Singer-Sam J, Grant M, LeBon JM, Okuyama K, Chapman V, Monk M, et al. Use of a Hpall-polymerase chain reaction assay to study DNA methylation in the Pgk-I CpG island of mouse embryos at the time of $\mathrm{X}$-chromosome inactivation. Mol Cell Biol 1990; I0: 4987-4989.

16. Sepulveda AR, Jones D, Ogino S, Samowitz W, Gulley ML, Edwards R, et al. CpG methylation analysis--current status of clinical assays and potential applications in molecular diagnostics: a report of the Association for Molecular Pathology. | Mol Diagn 2009; I I: 266-278.

17. Rother KI, Silke J, Georgiev O, Schaffner W, Matsuo K. Influence of DNA sequence and methylation status on bisulfite conversion of cytosine residues. Anal Biochem 1995; 231: 263265.

I8. Herman JG, Graff JR, Myohanen S, Nelkin BD,
Baylin SB. Methylation-specific PCR: a novel PCR assay for methylation status of CpG islands. Proc Natl Acad Sci U S A 1996; 93: 9821-9826.

19. Esteller M, Corn PG, Baylin SB, Herman JG. A gene hypermethylation profile of human cancer. Cancer Res 200 I; 61: 3225-3229.

20. Galm O, Yoshikawa H, Esteller M, Osieka R, Herman JG. SOCS- I, a negative regulator of cytokine signaling, is frequently silenced by methylation in multiple myeloma. Blood 2003; I01: 2784-2788.

21. Sasaki M, Anast J, Bassett W, Kawakami T, Sakuragi N, Dahiya R. Bisulfite conversion-specific and methylation-specific PCR: a sensitive technique for accurate evaluation of CpG methylation. Biochem Biophys Res Commun 2003; 309: 305-309.

22. Munson K, Clark J, Lamparska-Kupsik K, Smith SS. Recovery of bisulfite-converted genomic sequences in the methylation-sensitive QPCR. Nucleic Acids Res 2007; 35: 2893-2903.

23. Sriraksa R, Chaopatchayakul P, Jearanaikoon $P$, Leelayuwat $C$, Limpaiboon $T$. Verification of complete bisulfite modification using Calponin-specific primer sets. Clin Biochem 2010; 43: 528-530.

24. Hernandez HG, Tse MY, Pang SC, Arboleda H, Forero DA. Optimizing methodologies for PCRbased DNA methylation analysis. Biotechniques 2013; 55: | 81-197.

25. Wang YL, Qian J, Lin J, Yao DM, Qian Z, Zhu $\mathrm{ZH}$, et al. Methylation status of DDIT3 gene in chronic myeloid leukemia. J Exp Clin Cancer Res 2010; 29: 54

26. Bodoor K, Haddad Y, Alkhateeb A, Al-Abbadi A, Dowairi M, Magableh A, et al. DNA hypermethylation of cell cycle ( $p / 5$ and $p / 6)$ and apoptotic ( $p \mid 4, p 53$, DAPK and TMSI) genes in peripheral blood of leukemia patients. Asian Pac I Cancer Prev 20|4; 15: 75-84.

27. Ahmad I, Mir R, Javid J, Farooq S, Yadav P, Zuberi M, et al. Epigenetic Silencing of PI 6 (INK4a) Gene by Promoter Hypermethylation in Chronic Myelogenous Leukemia. Clin Lymphoma Myeloma Leuk 20I4; I4: SI39.

28. Li Y, Yang L, Pan Y, Yang J, Shang Y, Luo J. Methylation and decreased expression of SHP-I are related to disease progression in chronic myelogenous leukemia. Oncol Rep 2014; 31: 24382446.

29. San Jose-Eneriz E, Agirre $X$, Jimenez-Velasco A Cordeu L, Martin V, Arqueros V, et al. Epigenetic down-regulation of BIM expression is associated with reduced optimal responses to imatinib treatment in chronic myeloid leukaemia. Eur Cancer 2009; 45: 1877-1889.

30. Qian J, Qian Z, Lin J, Yao DM, Chen Q, Li Y, et al. Abnormal methylation of GRAF promoter Chinese patients with acute myeloid leukemia. 
Leuk Res 20II; 35: 783-786

31. Benetatos L, Hatzimichael E, Dasoula A, Dranitsaris G, Tsiara S, Syrrou M, et al. CpG methylation analysis of the MEG3 and SNRPN imprinted genes in acute myeloid leukemia and myelodysplastic syndromes. Leuk Res 2010; 34: I48-I53.

32. Yao DM, Qian J, Lin J, Wang YL, Chen Q, Qian Z, et al. Aberrant methylation of CCAAT/enhancer binding protein zeta promoter in acute myeloid leukemia. Leuk Res 201 I; 35: 957-960.

33. Xu Z, Wang M, Wang L, Wang Y, Zhao X, Rao $Q$, et al. Aberrant expression of TSC2 gene in the newly diagnosed acute leukemia. Leuk Res 2009; 33: 89|-897.

34. Ghasemi A, Rostami S, Chahardouli B, Alizad Ghandforosh N, Ghotaslou A, Nadali F. Study of SFRPI and SFRP2 methylation status in patients with de novo Acute Myeloblastic Leukemia. Int J Hematol Oncol Stem Cell Res 20I5; 9: |5-2|.

35. Tao YF, Xu LX, Lu J, Cao L, Li ZH, Hu SY, et al. Metallothionein III (MT3) is a putative tumor suppressor gene that is frequently inactivated in pediatric acute myeloid leukemia by promoter hypermethylation. J Transl Med 2014; 12: 182.

36. Paixao VA, Vidal DO, Caballero OL, Vettore AL, Tone LG, Ribeiro KB, et al. Hypermethylation of $C p G$ island in the promoter region of CALCA in acute lymphoblastic leukemia with central nervous system (CNS) infiltration correlates with poorer prognosis. Leuk Res 2006; 30: $89 \mid-894$.

37. Forsterova K, Votavova H, Schwarz J, Karban J, Stuka C, Trneny M. Advanced rai stage in patients with chronic lymphocytic leukaemia correlates with simultaneous hypermethylation of plural tumour suppressor genes. Folia Biol (Praha) 2010; 56: 158-164.

38. Montiel-Duarte C, Cordeu L, Agirre X, RomanGomez J, Jimenez-Velasco A, Jose-Eneriz ES, et al. Resistance to Imatinib Mesylate-induced apoptosis in acute lymphoblastic leukemia is associated with PTEN down-regulation due to promoter hypermethylation. Leuk Res 2008; 32: 709-7|6.

39. Shen L, Waterland RA. Methods of DNA methylation analysis. Curr Opin Clin Nutr Metab Care 2007; 10: 576-581.

40. Xiong Z, Laird PW. COBRA: a sensitive and quantitative DNA methylation assay. Nucleic Acids Res 1997; 25: 2532-2534.

4I. Brena RM, Auer H, Kornacker K, Hackanson B, Raval A, Byrd JC, et al. Accurate quantification of DNA methylation using combined bisulfite restriction analysis coupled with the Agilent 2100 Bioanalyzer platform. Nucleic Acids Res 2006; 34: el7.

42. Chen HC, Chang YS, Chen SJ, Chang PL. Deter- mination of the heterogeneity of DNA methylation by combined bisulfite restriction analysis and capillary electrophoresis with laser-induced fluorescence. J Chromatogr A 20 12; 1230: 123-129.

43. Kneip C, Schmidt B, Fleischhacker M, Seegebarth $A$, Lewin J, Flemming $N$, et al. A novel method for sensitive and specific detection of DNA methylation biomarkers based on DNA restriction during PCR cycling. Biotechniques 2009; 47: 737-744.

44. Wang CX, Wang X, Liu HB, Zhou ZH. Aberrant DNA methylation and epigenetic inactivation of hMSH2 decrease overall survival of acute lymphoblastic leukemia patients via modulating cell cycle and apoptosis. Asian Pac I Cancer Prev 2014; 15: 355-362

45. Hesson LB, Dunwell TL, Cooper WN, Catchpoole D, Brini AT, Chiaramonte R, et al. The novel RASSF6 and RASSFIO candidate tumour suppressor genes are frequently epigenetically inactivated in childhood leukaemias. Mol Cancer 2009; 8: 42

46. Thathia SH, Ferguson S, Gautrey HE, van Otterdijk SD, Hili M, Rand V, et al. Epigenetic inactivation of TWIST2 in acute lymphoblastic leukemia modulates proliferation, cell survival and chemosensitivity. Haematologica 2012; 97: $37 \mid-378$.

47. Strathdee G, Holyoake TL, Sim A, Parker A, Oscier DG, Melo JV, et al. Inactivation of HOXA genes by hypermethylation in myeloid and lymphoid malignancy is frequent and associated with poor prognosis. Clin Cancer Res 2007; I3: 50485055.

48. Wattanawaraporn R, Singhsilarak T, Nuchprayoon I, Mutirangura A. Hypermethylation of TTCI2 gene in acute lymphoblastic leukemia. Leukemia 2007; 21: 2370-2373.

49. Irving L, Mainou-Fowler T, Parker A, Ibbotson RE, Oscier DG, Strathdee G. Methylation markers identify high risk patients in IGHV mutated chronic lymphocytic leukemia. Epigenetics 2011; 6: 300-306.

50. Jiang M, Zhang Y, Fei J, Chang X, Fan W, Qian $X$, et al. Rapid quantification of DNA methylation by measuring relative peak heights in direct bisulfite-PCR sequencing traces. Lab Invest 20 I0; 90: 282-290.

51. Applied Biosystems. Methylation Analysis by Bisulfite Sequencing: Chemistry, Products and Protocols from Applied Biosystems. 2007.

52. Clark SJ, Statham A, Stirzaker C, Molloy PL, Frommer M. DNA methylation: bisulphite modification and analysis. Nat Protoc 2006; I: 2353 2364.

53. Frommer M, McDonald LE, Millar DS, Collis CM, Watt F, Grigg GW, et al. A genomic sequencing protocol that yields a positive display 
of 5-methylcytosine residues in individual DNA strands. Proc Natl Acad Sci U S A 1992; 89: |827-|83|.

54. Warnecke PM, Stirzaker C, Song J, Grunau C Melki JR, Clark SJ. Identification and resolution of artifacts in bisulfite sequencing. Methods 2002; 27: $101-107$

55. Grunau C, Clark SJ, Rosenthal A. Bisulfite genomic sequencing: systematic investigation of critical experimental parameters. Nucleic Acids Res 2001; 29: E65-65.

56. Lewin J, Schmitt AO, Adorjan P, Hildmann T, Piepenbrock C. Quantitative DNA methylation analysis based on four-dye trace data from direct sequencing of PCR amplificates. Bioinformatics 2004; 20: 3005-30I2.

57. Colella S, Shen L, Baggerly KA, Issa JP, Krahe R. Sensitive and quantitative universal Pyrosequencing methylation analysis of CpG sites. Biotechniques 2003; 35: 146-150.

58. Tost J, Dunker J, Gut IG. Analysis and quantification of multiple methylation variable positions in CpG islands by Pyrosequencing. Biotechniques 2003; 35: I52-I56.

59. Kim SY, Hwang SH, Song EJ, Shin HJ, Jung JS, Lee EY. Level of HOXA5 hypermethylation in acute myeloid leukemia is associated with short-term outcome. Korean J Lab Med 20 I0; 30: 469-473.

60. Baragano Raneros A, Martin-Palanco V, Fernandez AF, Rodriguez RM, Fraga MF, Lopez-Larrea $C$, et al. Methylation of NKG2D ligands contributes to immune system evasion in acute myeloid leukemia. Genes Immun 2015; 16: 7I-82.

6I. Li ZG, Jiao Y, Li WJ, Deng GR, Cui L, Gao C, et al. Hypermethylation of two CpG sites upstream of CASP8AP2 promoter influences gene expression and treatment outcome in childhood acute lymphoblastic leukemia. Leuk Res 2013; 37: |287-1293.

62. Bohne A, Schlee C, Mossner M, Thibaut J, Heesch S, Thiel E, et al. Epigenetic control of differential expression of specific ERG isoforms in acute T-lymphoblastic leukemia. Leuk Res 2009; 33: $817-822$

63. Queiros AC, Villamor N, Clot G, MartinezTrillos A, Kulis M, Navarro A, et al. A B-cel epigenetic signature defines three biologic subgroups of chronic lymphocytic leukemia with clinical impact. Leukemia 20।4; Sep 19 [Epub ahead of print].

64. Romero A, Blanco F. Aplicación de los microarrays en el laboratorio clínico. Ed Cont Lab Clín 2012; 15: 112-118

65. Wilhelm-Benartzi CS, Koestler DC, Karagas MR, Flanagan JM, Christensen BC, Kelsey KT, et al. Review of processing and analysis methods for DNA methylation array data. $\mathrm{Br}$ I Cancer 2013; 109: | 394- | 402.
66. Heyn H, Esteller M. DNA methylation profiling in the clinic: applications and challenges. Nat Rev Genet 2012; 13: 679-692.

67. Jiang Q, Liu CX, Gu X, Wilt G, Shaffer J, Zhang Y, et al. EpiTect Methyl II PCR Array System: A simple tool for screening regional DNA methylation of a large number of genes or samples without bisulfite conversion. SABiosciences, Qiagen. 2012. Disponible: http://www.sabiosciences. com/manuals/WP_ADNA_EpiTectMethyl2.pdf. Consultado: febrero 2015

68. Schumacher A, Kapranov P, Kaminsky Z, Flanagan J, Assadzadeh A, Yau $P$, et al. Microarray-based DNA methylation profiling: technology and applications. Nucleic Acids Res 2006; 34 $528-542$.

69. Bock C. Analysing and interpreting DNA methylation data. Nat Rev Genet 2012; 13: 705-719.

70. Chin YM, Mohd-Yacob A, Ramachandran S, Zakaria Z. DNA Methylation of SLC5A8, a Tumor Suppressor Gene in Chronic Myeloid Leukemia. IJHSR 20। 4; 4: 55-60.

7I. Stumpel DJ, Schneider P, van Roon EH, Boer JM, de Lorenzo P, Valsecchi MG, et al. Specific promoter methylation identifies different subgroups of MLL-rearranged infant acute lymphoblastic leukemia, influences clinical outcome, and provides therapeutic options. Blood 2009; I|4: 5490-5498.

72. Vilas-Zornoza A, Agirre $X$, Martin-Palanco $V$, Martin-Subero JI, San Jose-Eneriz E, Garate L, et al. Frequent and simultaneous epigenetic inactivation of TP53 pathway genes in acute lymphoblastic leukemia. PLoS One 201 I; 6: el7012.

73. Wilop S, Fernandez AF, Jost E, Herman JG Brummendorf TH, Esteller M, et al. Array-based DNA methylation profiling in acute myeloid leukaemia. Br J Haematol 20। I; I 55: 65-72.

74. Kurkjian C, Kummar S, Murgo AJ. DNA methylation: its role in cancer development and therapy. Curr Probl Cancer 2008; 32: 187-235.

75. Eads CA, Danenberg KD, Kawakami K, Saltz LB, Blake C, Shibata D, et al. MethyLight: a high-throughput assay to measure DNA methylation. Nucleic Acids Res 2000; 28: E32.

76. Wojdacz TK, Dobrovic A, Hansen LL. Methylation-sensitive high-resolution melting. Nat Protoc 2008; 3: 1903-1908.

77. Zeschnigk M, Bohringer S, Price EA, Onadim Z, Masshofer L, Lohmann DR. A novel real-time PCR assay for quantitative analysis of methylated alleles (QAMA): analysis of the retinoblastoma locus. Nucleic Acids Res 2004; 32: el 25

78. Gonzalgo ML, Jones PA. Rapid quantitation of methylation differences at specific sites using methylation-sensitive single nucleotide primer extension (Ms-SNuPE). Nucleic Acids Res 1997; 25 2529-2531. 